\title{
The neutrophil to lymphocyte ratio is an independent predictor for severe COVID-19
}

\section{Evidence from a multicenter case-control study and meta-analyses}

\author{
Jiangli Cheng · Aijia Ma · Jing Yang · Meiling Dong · Xuelian Liao · Yan Kang
}

Received: 22 July 2020 / Accepted: 30 June 2021 / Published online: 3 August 2021

(C) The Author(s) 2021

\begin{abstract}
Summary
Purpose The aim of this study was to determine whether the neutrophil to lymphocyte ratio (NLR) can predict severe Coronavirus disease 2019 (COVID19).

Patients and methods A multicenter case-control study was conducted to investigate whether the NLR can help predict the severity of COVID-19. Patients confirmed to have COVID-19 between 16 January 2020 and 15 March 2020 were enrolled. Furthermore, meta-analyses were conducted based on both previous studies and our case-control study.

Results In the case-control study, 213 patients (severe: 81 ) were included. The results suggested that the NLR was an independent risk factor (odds ratio [OR], $1.155,95 \%$ confidence interval [95\% CI]: 1.043-1.279, $P=0.006$ ) and a great predictor (the area under the ROC curve was $0.728,95 \%$ CI: $0.656-0.800$ ) for severe COVID-19. In total, 18 datasets from 16 studies combined with our case-control study (severe: 1211; non-severe: 5838) were included in the meta-analyses and the results showed that the NLR of the severe
\end{abstract}

Consent for publication: not applicable

Availability of data and materials: the datasets used and/or analyzed during the current study are available from the corresponding author on reasonable request.

Jiangli Cheng, Aijia Ma, and Jing Yang contributed to the work equally.

Supplementary Information The online version of this article (https://doi.org/10.1007/s00508-021-01917-9)

contains supplementary material, which is available to authorized users.

J. Cheng $\cdot$ A. Ma $\cdot$ J. Yang $\cdot$ M. Dong $\cdot$ X. Liao $\cdot$ Y. Kang $(\bowtie)$ Department of Critical Care Medicine, West China Hospital of Sichuan University, No. 37, Guoxue Alley, 610041 Chengdu, Sichuan Province, China kangyan@scu.edu.cn
COVID-19 group was significantly higher than that of the non-severe group ( $\mathrm{SMD}=1.10,95 \% \mathrm{CI}$ : $0.90-1.31$, $P<0.001$ ). Based on the $2 \times 2$ data from 6 studies, the SROC of NLR for predicting severe COVID-19 was 0.802 , with a sensitivity of 0.67 (95\% CI: $0.61-0.72)$ and a specificity of 0.75 (95\% CI: $0.73-0.78$ ).

Conclusion Based on a multicenter case-control study and a meta-analysis, we found that the initial NLR was a great predictor of severe COVID-19.

Keywords Coronavirus disease 2019 - Neutrophil · Lymphocyte $\cdot$ Risk factor - Severity

\begin{tabular}{ll}
\multicolumn{2}{l}{ List of abbreviations } \\
ALT & Alanine aminotransferase \\
AST & Aspartate aminotransferase \\
COVID-19 & Coronavirus disease 2019 \\
NLR & Neutrophil to lymphocyte ratio \\
PLR & Platelet to lymphocyte ratio \\
ROC & Receiver operating characteristic \\
SMD & Standardized mean difference \\
SROC & Summary receiver operating characteris- \\
& tic
\end{tabular}

\section{Introduction}

The current pandemic of coronavirus disease 2019 (COVID-19) has spread rapidly all over the world [1]. To date, more than 11.8 million people worldwide have been diagnosed with COVID-19: among them 20-30\% have developed into severe COVID-19 [2]. According to previous studies, the mortality rate of severe COVID-19 patients is approximately 20 times higher than that of non-severe COVID-19 patients, up to $61.5 \%[3,4]$. A sudden transition to severe COVID19 is common for patients with mild symptoms [5]. Clinical deterioration will lead to the consumption of medical resources, intensive care beds, ventilators, 
and adverse outcomes of the patients. Hence, it is very important to identify an efficient predictor for the early identification and targeting of potentially severe patients to improve the clinical outcomes of patients with COVID-19.

COVID-19 is characterized by uncontrolled inflammatory storms [6]. The neutrophil to lymphocyte ratio (NLR), a routinely measured inflammatory biomarker, reflects the immune status of the human defence system against infection. A higher NLR, which results in an increased neutrophil or/and decreased lymphocyte count, might indicate that the patient had severe inflammatory progression [7]. Some studies have reported that the NLR could be useful for the diagnosis of sepsis and might be a good predictor for a poor prognosis of acute respiratory distress syndrome, which has the same disease characteristics as COVID-19, to some extent [8-10]. Previous studies of COVID-19 have noted the predictive power of the NLR for clinical deterioration and mortality among COVID19 patients [11-13]; however, whether NLR can predict severe COVID-19 is still controversial. Thus, a multicenter case-control study and meta-analysis was conducted to estimate the potential predictive value of the NLR for severe COVID-19.

\section{Material and methods}

\section{Case-control study}

\section{Study design and participants}

In total, 213 patients (3 patients were excluded due to missing NLR data at admission) with confirmed COVID-19 from 21 hospitals in Sichuan Province between 16 January 2020 and 15 March 2020 were included in the analysis: among them, 81 patients were defined as having severe COVID-19. The definitions of COVID-19 and severe COVID-19 were described in a previously published article [14]. The protocol was approved by the Ethics Committee of the West China Hospital of Sichuan University and the participating hospitals, and informed consent was obtained. The study was registered and the registration number was ChiCTR2000029758.

\section{Data collection}

We conducted the study based on the electronic data capture and analysis system for each included patient. Demographic characteristics, comorbidities, symptoms, signs and laboratory findings at admission were collected. The NLR is the ratio of neutrophil count to lymphocyte count, and platelet to lymphocyte ratio (PLR) is the ratio of platelet count to lymphocyte count.

\section{Statistical analysis}

Categorical variables are expressed as numbers and percentages, continuous normally distributed variables are expressed as the mean and standard devia- tion, and continuous skewness-distributed variables are expressed as the median and interquartile range. The $\chi^{2}$-test, t-test and Mann-Whitney $U$ test were used to compare the differences between severe and non-severe COVID-19 groups. A 2-tailed $P$ value lower than 0.05 was considered to be statistically significant. Variables found to be statistically significant in univariate analysis were included in the multivariate logistic regression analysis to identify the independent risk factors for severe COVID-19. The odds ratio (OR) and its 95\% confidence interval (CI) were used as binary parameters. The Cochran-Armitage test for trend and the area under the receiver operating characteristic (ROC) curve were used to analyze the linear relationship of NLR level with the rate of severe COVID-19 and the ability of NLR to predict severe COVID-19, respectively.

\section{Meta-analyses}

This meta-analysis conformed to the preferred reporting items for system review and meta-analysis (PRISMA) statement ([15]; Additional file 1).

\section{Data search}

PubMed, EMBASE, Web of Science, MedRxiv and BioRxiv, the WanFang database and the China National Knowledge Infrastructure (CNKI) were searched through inception to May 2020. The search terms of 'neutrophil-to-lymphocyte ratio' OR 'NLR' and 'COVID-19' were used to identify studies that reported the relationship between NRL and the severity of COVID-19. The reference lists of the included studies were examined to identify any other potentially qualified studies.

\section{Study selection}

Two reviewers reviewed the titles and abstracts independently to determine whether they needed full-text review according to the following inclusion and exclusion criteria. After that the full-text review of the studies was completed to identify the articles included by the same two reviewers. When the opinions were inconsistent, the question was discussed and determined by a third reviewer.

Inclusion and exclusion criteria Studies meeting the following criteria were included:

1. Patients diagnosed with COVID-19 and could be divided into severe and non-severe COVID-19 groups.

2. The data of NLR were available and be compared between the severe and non-severe COVID-19 groups.

Studies with the following criteria were excluded:

1. Articles not written in English or Chinese

2. Insufficient data for analysis.

3. Repeated published data. 
Table 1 Characteristics of the study population

\begin{tabular}{|c|c|c|c|c|}
\hline Variables & $\begin{array}{l}\text { Total } \\
(n=213)\end{array}$ & $\begin{array}{l}\text { Mild COVID-19 } \\
(n=132)\end{array}$ & $\begin{array}{l}\text { Severe COVID-19 } \\
(n=81)\end{array}$ & $P$ \\
\hline \multicolumn{5}{|l|}{ Characteristics } \\
\hline Age, years & $47(33,59)$ & $43(31,54)$ & $50(39,65)$ & 0.000 \\
\hline Gender/case (\%) & & & & 0.102 \\
\hline Male & $119(55.9 \%)$ & $68(51.5 \%)$ & $51(63 \%)$ & - \\
\hline Female & $94(44.1 \%)$ & $64(48.5 \%)$ & $30(37 \%)$ & - \\
\hline $\mathrm{BMI} /\left(\mathrm{kg} / \mathrm{m}^{2}\right)$ & $23.0(21.1,25.9)$ & $22.6(20.8,24.5)$ & $24.0(21.5,27.3)$ & 0.013 \\
\hline \multicolumn{5}{|l|}{ Chronic medical illness/case (\%) } \\
\hline Diabetes & $25(11.7 \%)$ & $7(5.3 \%)$ & $18(22.2 \%)$ & 0.000 \\
\hline Hypertension & $22(10.3 \%)$ & $7(5.3 \%)$ & $15(18.5 \%)$ & 0.002 \\
\hline Chronic pulmonary disease & $15(7.0 \%)$ & $4(3 \%)$ & $11(13.6 \%)$ & 0.003 \\
\hline \multicolumn{5}{|l|}{ Signs and symptoms } \\
\hline Fever $\left(>37.3^{\circ} \mathrm{C}\right)$ & $150(70.4 \%)$ & $81(61.4 \%)$ & $69(85.2 \%)$ & 0.000 \\
\hline Dry cough/case (\%) & $100(46.9 \%)$ & $60(45.5 \%)$ & $40(49.4 \%)$ & 0.577 \\
\hline Sputum production/case (\%) & $73(34.3 \%)$ & $35(26.5 \%)$ & $38(46.9 \%)$ & 0.002 \\
\hline Fatigue/case (\%) & $59(27.7 \%)$ & $29(22 \%)$ & $30(37 \%)$ & 0.017 \\
\hline Dyspnea/case (\%) & $37(17.4 \%)$ & $12(9.1 \%)$ & $25(30.9 \%)$ & 0.000 \\
\hline Mean arterial pressure/mm Hg & $94.67(87.17,101.67)$ & $93(85.5,99.9)$ & $96(89.7,106.2)$ & 0.012 \\
\hline Heart rate/(beats/min) & $90(80,98)$ & $88(80,96)$ & $90(86,101.5)$ & 0.031 \\
\hline Respiratory rate/(breaths/min) & $20(20,21)$ & $20(20,21)$ & $21(20,23)$ & 0.000 \\
\hline Pulse oxygen saturation/\% & $97(95,98)$ & $98(96,98)$ & $95.5(91.75,97)$ & 0.000 \\
\hline \multicolumn{5}{|l|}{ Blood laboratory findings } \\
\hline White blood cell count $/ 10^{\wedge} 9 / \mathrm{L}$ & $5.41(4.08,7.08)$ & $5.30(4.14,6.92)$ & $5.73(4.05,7.61)$ & 0.153 \\
\hline Neutrophil count/10^9/L & $3.65(2.63,5.24)$ & $3.38(2.56,4.72)$ & $4.37(2.91,6.40)$ & 0.001 \\
\hline Lymphocyte count/10^9/L & $0.99(0.67,1.51)$ & $1.25(0.83,1.68)$ & $0.73(0.51,1.05)$ & 0.000 \\
\hline NLR & $3.28(2.22,5.80)$ & $2.88(2.07,4.16)$ & $5.41(2.90,9.87)$ & 0.000 \\
\hline Platelet count $/ 10^{\wedge} 9 / \mathrm{L}$ & $168(132.5,216.5)$ & $180.5(140.25,224.25)$ & $151(126.5,205)$ & 0.064 \\
\hline PLR & $169.86(112.04,258.20)$ & $139.91(107.09,218.77)$ & $206.3(141.1,338.68)$ & 0.000 \\
\hline Hemoglobin/(g/L) & $138(125,150)$ & $138(126,150)$ & $137(123,150)$ & 0.319 \\
\hline Total bilirubin/( $\mu \mathrm{mol} / \mathrm{L})$ & $8.85(5.9,14.5)$ & $8.4(5.6,14)$ & $9.2(6.35,15.2)$ & 0.228 \\
\hline AST/(IU/L) & $29(23,38.5)$ & $28(22,35)$ & $32(25,44.68)$ & 0.006 \\
\hline ALT/(IU/L) & $26(16,41)$ & $22(16,39)$ & $30(17.5,45.25)$ & 0.060 \\
\hline Creatinine/( $(\mu \mathrm{mol} / \mathrm{L})$ & $67.8(53.85,78.68)$ & $66(52.48,76)$ & $69.75(54.63,80)$ & 0.064 \\
\hline Lactic acid/(mmol/L) & $1.6(1.2,2.1)$ & $1.6(1.2,1.9)$ & $1.62(1.2,2.3)$ & 0.383 \\
\hline
\end{tabular}

4. Reviews, systematic reviews, meta-analyses, guidelines, study protocols, case reports, letters, correspondences, comments or editorials.

\section{Data extraction}

Data were extracted using the predesigned data collection table. Two reviewers extracted data from all included studies independently. The collected data included author, year, study design, study location, study samples, NLR values, age and sex. When the opinions were inconsistent, the question was discussed and determined by a third reviewer.

Assessment of study quality

Studies were evaluated by the Newcastle-Ottawa assessment tool, for which the maximum score was
9 points and a score of 7 or greater was considered to be a low risk of bias [16]. Two reviewers assessed the risk of bias of all of the included studies independently; when opinions were inconsistent, the question was discussed and determined by a third reviewer.

\section{Data synthesis and analysis}

The software Stata version 16.0 (STATA Corporation, College Station, TX, USA) and Meta-Disc, version 1.4 (Unit of Clinical Biostatistics team of the Ramón y Cajal Hospital, Madrid, Spain) were used to conduct the statistical analysis. The median and interquartile range were transformed into mean and standard deviation based on a previously proven formula; [17, 18]. Standardized mean differences (SMDs) and corresponding 95\% confidence intervals (CIs) were used 
Fig. 1 The occurrence rate of severe COVID-19 of each quartile of NLR

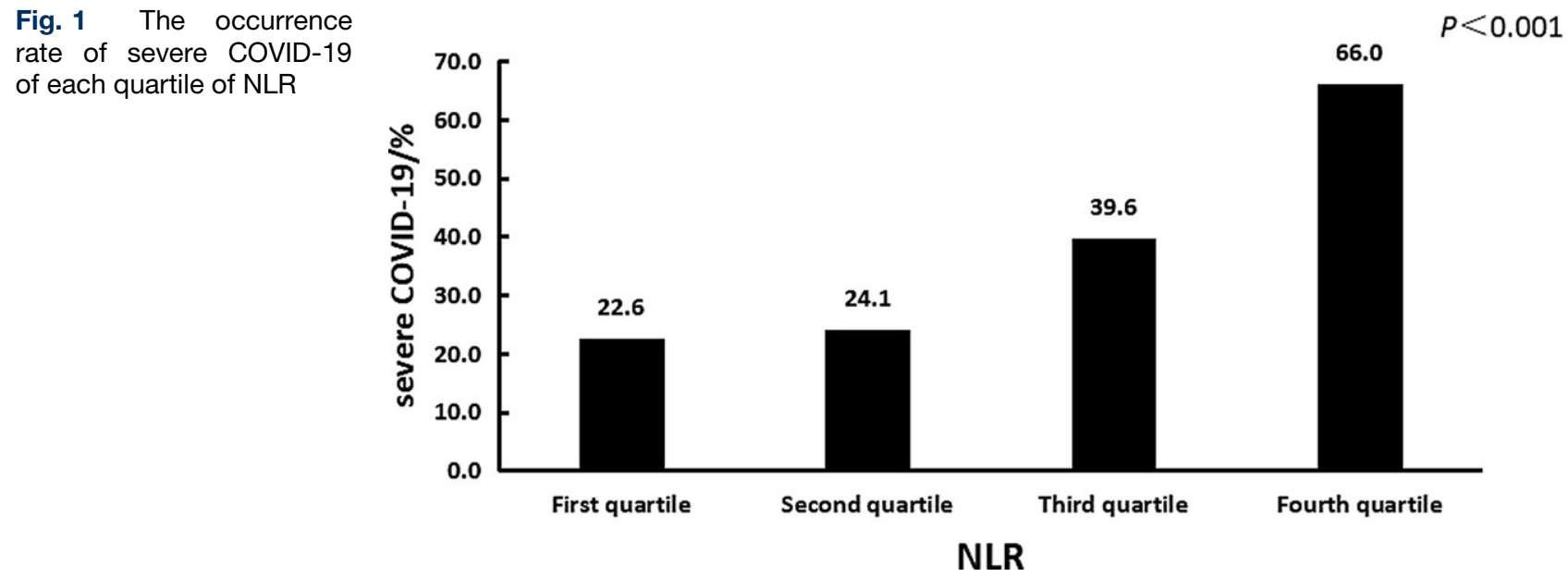

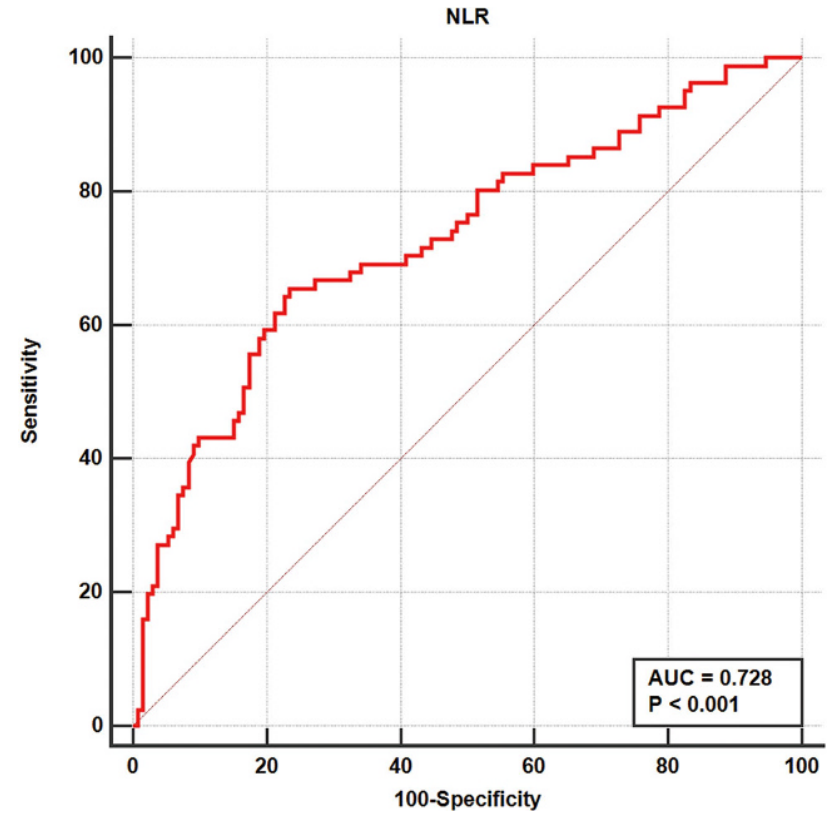

Fig. 2 The ROC curve in predicting severe COVID-19 of NLR

to evaluate the differences in NLR between the severe COVID-19 and non-severe COVID-19 groups. Heterogeneity among the studies was evaluated using Cochran's Q test and the $\mathrm{I}^{2}$ statistic. An $\mathrm{I}^{2}$ index of $50 \%$ or greater and a $p$-value less than 0.1 were taken to indicate significant statistical heterogeneity. When statistical heterogeneity existed, a random effects model was used. Publication bias was assessed by Egger's and Begg's tests [19]. Subgroup analyses were performed according to the mean age ( $>50$ years or $\leq 50$ years) and study location (the study included patients in Hubei or not).To further analyze the predictive power of the NLR in severe COVID-19, $2 \times 2$ data points were obtained from the studies. The area under summary receiver operating characteristic (SROC), Q index, sensitivity and specificity with $95 \%$ CI were calculated.

\section{Results}

\section{Case-control study}

A total of 213 patients were enrolled in the final analysis, with 81 severe COVID-19 patients. Among the included patients, 94 (44.1\%) patients were female; the median age was 47 years $(33,59$ years); fever was the most common symptom before admission, and diabetes was the most common comorbidity. Age, body mass index, mean arterial pressure, heart rate, respiratory rate, neutrophil count, NLR, PLR, aspartate aminotransferase and alanine aminotransferase were higher in the severe COVID-19 group than in the non-severe group, and pulse oxygen saturation and lymphocyte count were lower in the severe COVID-19 group. Severe COVID-19 patients were more likely to have fever, sputum production, fatigue, dyspnea, diabetes, hypertension and chronic pulmonary disease (see Table 1).

For all patients, the median NLR was 3.28 (2.22, $5.80)$, with $2.88(2.07,4.16)$ in the non-severe group and $5.41(2.90,9.87)$ in the severe COVID-19 group. Variables found to be statistically significant $(P<0.05)$ in univariate analysis were included in the multivariate logistic regression analysis to identify the independent risk factors for severe COVID-19. After adjustment for confounders, the NLR was found to be an independent risk factor for severe COVID-19 (OR, $1.155,95 \%$ CI, 1.043-1.279, $P=0.006$ ).

The patients were divided into 4 groups according to the interquartile NLR, they were less than 2.22 , $2.22-3.28,3.28-5.80$ and greater than 5.80 . The occurrence rates of severe COVID-19 in each quartile group were calculated, and were $22.6 \%, 24.1 \%, 39.6 \%$ and $66 \%$ in the first quartile, second quartile, third quartile and fourth quartile, respectively. Based on the statistical analysis result of the Cochran-Armitage test for trend, there was a linear relationship between the NLR level and the occurrence rate of severe COVID19, which visibly increased with the increase in NLR $(P<0.001)$. The result is described in Fig. 1 . 
Fig. 3 The flow of citations reviewed and studies included
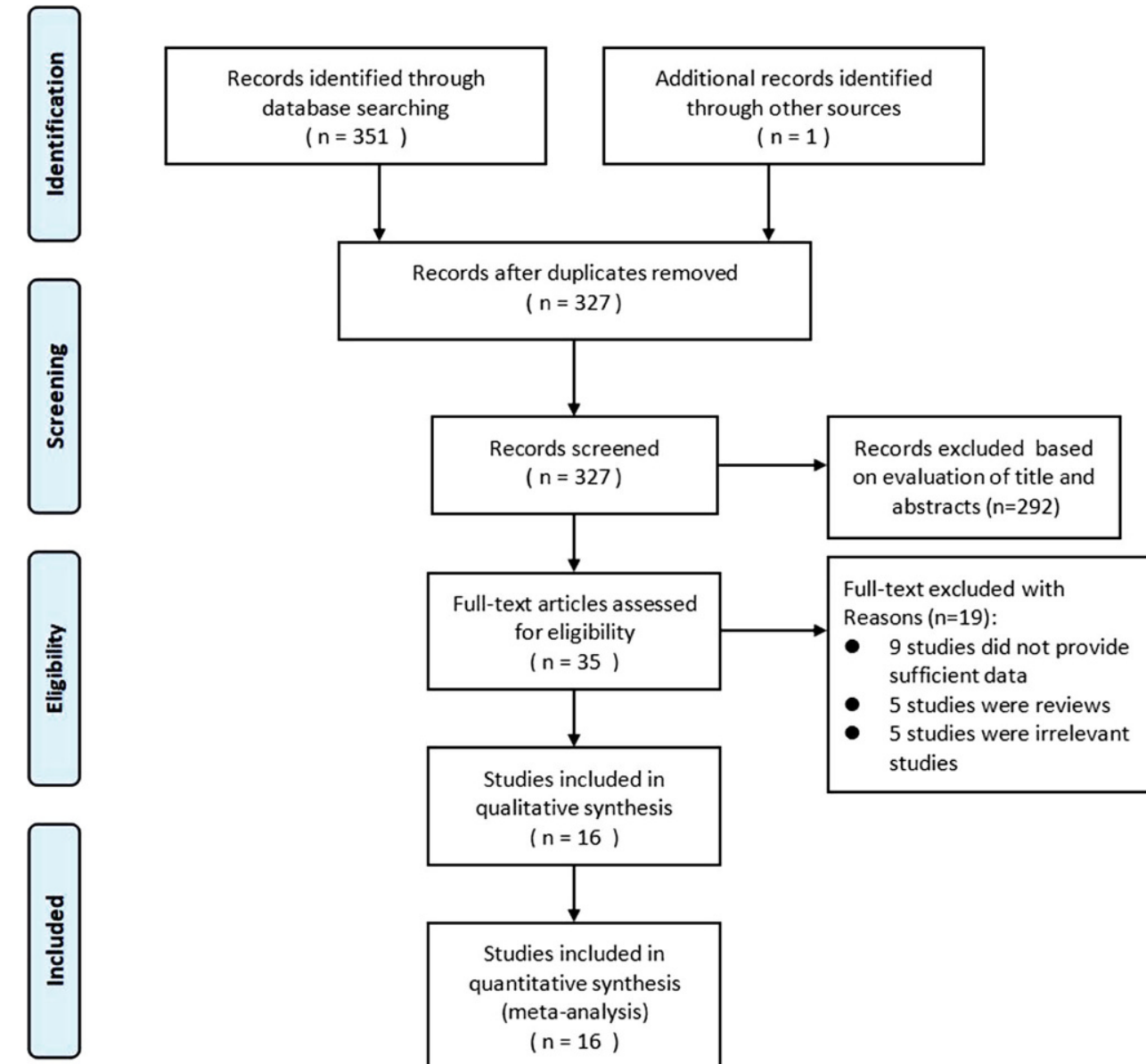

An ROC curve analysis was performed to analyze the ability of the NLR to predict severe COVID-19. The area under the ROC curve was 0.728 (95\% CI, $0.656-0.800$ ). The optimal cut-off value was 4.184 with a sensitivity of 0.654 and a specificity of 0.765 . The result is described in Fig. 2.

Multivariable analysis found that age $(P<0.001)$, body mass index $(P=0.038)$, fever $(P=0.012)$, sputum production $(P=0.019)$, respiratory rate $(P=0.004)$, pulse oxygen saturation $(P=0.001)$ and NLR $(P=0.006)$ contributed independently to severe COVID-19. The result is described in Additional file 2.

\section{Meta-analyses}

\section{Literature search and study selection}

Fig. 3 shows the work flow of the citations reviewed and the studies included. Our search strategy yielded 327 citations after de-duplication, and 35 potential citations were full-text reviewed. Finally, 16 citations were included. The study from Yabing Guo and Wenhua Liang reported 2 sets of data. Therefore, 19 datasets were included in the quantitative synthesis (18 datasets from 16 studies combined with our case-control study) [6, 20-34].

\section{Study characteristics}

A total of 7049 (6836 patients in the previous study and 213 patients in our study) patients were included, among whom 1211 (1130 patients in the previous study and 81 patients in our study) patients had severe COVID-19. The sample size of the individual studies ranged from 63 subjects to 1590 subjects. Only one study was from Britain, and all other studies were from China, with 8 studies included patients in Hubei. One of these studies was prospectively conducted, and all of the others were retrospectively. All studies reported patient ages, and the mean age of the patients in 5 studies was greater than 50 years old (see Table 2).

\section{Risk of bias of the included studies}

The Newcastle-Ottawa assessment tool was used to evaluate the quality of the included studies. All studies were considered to have a low risk of bias (Additional file 3). Among the included studies, no significant publication bias was found (Egger's test: $P=0.924$; Begg's test: $P=0.889$; Additional file 4).

Association of NLR with the severity of COVID-19 A total of 7049 patients from 19 datasets were analyzed. The pooled results showed that NLR were 
Table 2 Main characteristics of the included studies in the meta-analysis

\begin{tabular}{|c|c|c|c|c|c|c|}
\hline Author & Study design & Study location & Samples & NLR value & $\begin{array}{l}\text { Mean } \\
\text { age (years) }\end{array}$ & $\begin{array}{l}\text { Sex } \\
\text { (female \%) }\end{array}$ \\
\hline Qin et al. 2020 & Retrospective & Hubei, China & $\begin{array}{l}\text { Non-severe: } 166 \\
\text { Severe: } 286\end{array}$ & $\begin{array}{l}\text { Non-severe: } 3.2(1.8,4.9) \text { severe: } 5.5 \\
(3.3,10.0)\end{array}$ & 57.3 & $48.0 \%$ \\
\hline $\begin{array}{l}\text { Gong et al. } \\
2020\end{array}$ & Retrospective & $\begin{array}{l}\text { Guangdong and } \\
\text { Hubei, China }\end{array}$ & $\begin{array}{l}\text { Non-severe: } 161 \\
\text { Severe: } 28\end{array}$ & $\begin{array}{l}\text { Non-severe: } 1.9(1.4,2.9) \text { Severe: } 3.7 \\
(2.0,6.7)\end{array}$ & 49.2 & $53.4 \%$ \\
\hline Liu et al. 2020 & Prospective & Beijing, China & $\begin{array}{l}\text { Non-severe: } 44 \\
\text { Severe: } 17\end{array}$ & $\begin{array}{l}\text { Non-severe: } 2.2(1.4,3.1) \\
\text { Severe: } 3.6(2.5,5.4)\end{array}$ & 42.5 & $49.2 \%$ \\
\hline Yang et al. 2020 & Retrospective & Zhejiang, China & $\begin{array}{l}\text { Non-severe: } 69 \\
\text { Severe: } 24\end{array}$ & $\begin{array}{l}\text { Non-severe: } 4.8 \pm 3.5 \\
\text { Severe: } 20.7 \pm 24.1\end{array}$ & 46.4 & $39.8 \%$ \\
\hline $\begin{array}{l}\text { Zhang et al. } \\
2020\end{array}$ & Retrospective & Hubei, China & $\begin{array}{l}\text { Mild: } 84 \\
\text { Severe: } 31\end{array}$ & $\begin{array}{l}\text { Mild: } 2.28 \pm 1.29 \\
\text { Severe: } 7.58 \pm 7.04\end{array}$ & 49.5 & $57.4 \%$ \\
\hline Guo et al. 2020 & Retrospective & Guangdong, China & $\begin{array}{l}\text { Non-severe: } 753 \\
\text { Severe: } 65\end{array}$ & $\begin{array}{l}\text { Non-severe: } 1.95(1.36,2.95) \text { Severe: } \\
3.34(2.22-6.22)\end{array}$ & 43.4 & $51.6 \%$ \\
\hline Guo et al. 2020 & Retrospective & Hubei, China & $\begin{array}{l}\text { Non-severe: } 282 \\
\text { Severe: } 38\end{array}$ & $\begin{array}{l}\text { Non-severe: } 2.5(1.68,4.12) \text { Severe: } \\
4.48(2.06,8.49)\end{array}$ & 55.6 & $50 \%$ \\
\hline Feng et al. 2020 & Retrospective & Hunan, China & $\begin{array}{l}\text { Non-severe: } 126 \\
\text { Severe: } 15\end{array}$ & $\begin{array}{l}\text { Non-severe: } 3.4(1.9,3.9) \\
\text { Severe: } 5.2(3.1,6.9)\end{array}$ & 44.4 & $48.9 \%$ \\
\hline $\begin{array}{l}\text { Chen et al. } \\
2020\end{array}$ & Retrospective & Hunan, China & $\begin{array}{l}\text { Mild: } 29 \\
\text { Moderate: } 212 \\
\text { Severe: } 50\end{array}$ & $\begin{array}{l}\text { Mild: } 3.07(2.13,6.1) \text { Moderate: } 2.3 \\
(1.67,3.24) \\
\text { Severe: } 3.74(2.16,6.54)\end{array}$ & 46.4 & $50.2 \%$ \\
\hline $\begin{array}{l}\text { Wang et al. } \\
2020\end{array}$ & Retrospective & Multi-center, China & $\begin{array}{l}\text { Mild: } 86 \\
\text { Ordinary: } 486 \\
\text { Severe: } 63\end{array}$ & $\begin{array}{l}\text { Mild: } 2.73 \pm 2.28 \\
\text { Ordinary: } 3.58 \pm 3.07 \\
\text { Severe: } 9.38 \pm 10.52\end{array}$ & 44.9 & $48 \%$ \\
\hline $\begin{array}{l}\text { Huang et al. } \\
2020\end{array}$ & Retrospective & Hunan, China & $\begin{array}{l}\text { Non-severe: } 92 \\
\text { Severe: } 29\end{array}$ & $\begin{array}{l}\text { Non-severe: } 2.55 \pm 1.38 \\
\text { Severe: } 4.4 \pm 2.7\end{array}$ & 45.1 & $47.1 \%$ \\
\hline Xia et al. 2020 & Retrospective & Hubei, China & $\begin{array}{l}\text { Moderate: } 32 \\
\text { Severe: } 31\end{array}$ & $\begin{array}{l}\text { Moderate: } 2.89(1.77,5.55) \\
\text { Severe: } 8.78(5.77,25.10)\end{array}$ & 63.4 & $47.6 \%$ \\
\hline $\begin{array}{l}\text { Chen et al. } \\
2020\end{array}$ & Retrospective & Chongqing, Chian & $\begin{array}{l}\text { Non-severe: } 108 \\
\text { Severe: } 31\end{array}$ & $\begin{array}{l}\text { Non-severe: } 3.19(2.13,4.73) \\
\text { Severe: } 4.07(2.86,6.90)\end{array}$ & 45.3 & $45.3 \%$ \\
\hline Pan et al. 2020 & Retrospective & Hubei, China & $\begin{array}{l}\text { Non-severe: } 96 \\
\text { Severe: } 16\end{array}$ & $\begin{array}{l}\text { Non-severe: } 4.74(2.5,8.75) \\
\text { Severe: } 9.25(5.95,11.57)\end{array}$ & 61.3 & $62.7 \%$ \\
\hline $\begin{array}{l}\text { Liang et al. } \\
2020\end{array}$ & Retrospective & Multi-center, China & $\begin{array}{l}\text { Nonsevere: } 1459 \\
\text { Severe: } 131\end{array}$ & $\begin{array}{l}\text { Non-severe: } 4.4 \pm 3.8 \\
\text { Severe: } 12.7 \pm 12.4\end{array}$ & 48.9 & $42.7 \%$ \\
\hline $\begin{array}{l}\text { Liang et al. } \\
2020\end{array}$ & Retrospective & Multi-center, China & $\begin{array}{l}\text { Non-severe: } 642 \\
\text { Severe: } 87\end{array}$ & $\begin{array}{l}\text { Non-severe: } 4.3 \pm 3.8 \\
\text { Severe: } 17.1 \pm 20\end{array}$ & 48.2 & I \\
\hline $\begin{array}{l}\text { Ewan et al. } \\
2020\end{array}$ & Retrospective & Multi-center, Britain & $\begin{array}{l}\text { No ICU/death: } 393 \\
\text { ICU/death: } 159\end{array}$ & $\begin{array}{l}\text { No ICU/death: } 5.81 \pm 4.22 \\
\text { ICU/death: } 8.58 \pm 6.26\end{array}$ & 67 & $45.1 \%$ \\
\hline $\begin{array}{l}\text { Huang et al. } \\
2020\end{array}$ & Retrospective & Shanghai, China & $\begin{array}{l}\text { Nonsevere: } 386 \\
\text { Severe: } 29\end{array}$ & $\begin{array}{l}\text { Non-severe: } 2.67(1.76,3.42) \\
\text { Severe: } 4.16(3.14,14.65)\end{array}$ & 45.1 & $47.7 \%$ \\
\hline $\begin{array}{l}\text { Cheng et al. } \\
2021\end{array}$ & Retrospective & Sichuan, China & $\begin{array}{l}\text { Mild: } 132 \\
\text { Severe: } 81\end{array}$ & $\begin{array}{l}\text { Mild: } 2.88(2.07,4.16) \\
\text { Severe: } 5.41(2.90,9.87)\end{array}$ & 46.9 & $44.1 \%$ \\
\hline
\end{tabular}

higher in patients with severe COVID-19 than in those with non-severe COVID-19 (SMD $=1.10,95 \%$ CI: $0.90-1.31, P<0.001)$. High heterogeneity existed $\left(\mathrm{I}^{2}=87.1 \%, \quad P<0.001\right.$, a random-effects model was used) (see Fig. 4).

\section{Subgroup analyses}

To determine other parameters that might affect the predictive power of NLR for severe COVID-19, subgroup analyses were conducted according to the mean age ( $>50$ years or $\leq 50$ years) and study location (the study included patients from Hubei or not). The results showed that the mean age and the study location did not affect the predictive power of the NLR for severe COVID-19 (see Table 3 and Additional file 5).

\section{SROC}

The $2 \times 2$ data were obtained from 6 studies. In total, 1698 patients, including 278 severe COVID-19 patients, were included in the final analysis (see Additional file 6). The area under the SROC was 0.802 , and the Q index was 0.738 , with a sensitivity of 0.67 (95\% CI: $0.61-0.72)$ and a specificity of 0.75 (95\% CI: 0.73-0.78) (see Fig. 5).

\section{Discussion}

Currently, COVID-19 has spread rapidly around the world. Dysregulation of the immune response leads to clinical deterioration of patients with COVID-19, which results in increased mortality and consumption of medical resources. Early prediction and inter- 
Fig. 4 Forest plots of NLR between severe COVID-19 and non-severe COVID-19

Study
ID
Qin et al. 2020
Gong et al. 2020
Liu et al. 2020
Yang at al. 2020
Zhang et al. 2020
Guo et al. 2020
Guo at al. 2020
Feng et al. 2020
Chen et al. 2020
Wang et al. 2020
Huang et al. 2020
Xia et al. 2020

Table 3 Results of subgroup meta-analysis for predicting severe COVID-19 of NLR

\begin{tabular}{|c|c|c|c|c|c|c|}
\hline \multirow[t]{2}{*}{ Variables } & \multirow[t]{2}{*}{$N^{a}$} & \multirow[t]{2}{*}{ Case $^{b}$} & \multicolumn{2}{|l|}{ Pooled data } & \multicolumn{2}{|c|}{ Heterogeneity } \\
\hline & & & $\mathrm{HR}(95 \% \mathrm{Cl})$ & $P$ & 12 & $\mathrm{Ph}$ \\
\hline \multicolumn{7}{|l|}{ NLR } \\
\hline Severe vs. non-severe & 19 & 7049 & $1.104(0.900,1.308)$ & $<0.001$ & $87.1 \%$ & $<0.001$ \\
\hline \multicolumn{7}{|l|}{ By mean age } \\
\hline$>50$ years & 5 & 1499 & $0.706(0.569,0.842)$ & $<0.001$ & $14.2 \%$ & 0.324 \\
\hline$\leq 50$ years & 14 & 5550 & $1.228(1.022,1.434)$ & $<0.001$ & $80.7 \%$ & $<0.001$ \\
\hline \multicolumn{7}{|l|}{ By study location } \\
\hline Hubei & 8 & 3570 & $1.163(0.840,1.490)$ & $<0.001$ & $89.0 \%$ & $<0.001$ \\
\hline Other & 11 & 3479 & $1.062(0.801,1.312)$ & $<0.001$ & $83.8 \%$ & $<0.001$ \\
\hline \multicolumn{7}{|c|}{$\begin{array}{l}\text { SMD standardized mean difference, } 95 \% \text { Cl } 95 \% \text { cor } \\
\text { ity test } \\
\text { a Numbers of studies included in the meta-analysis. } \\
{ }^{b} \text { Number of patients of included studies. }\end{array}$} \\
\hline
\end{tabular}

vention for severe COVID-19 is essential to improve the prognosis of COVID-19 patients. The NLR represents the balance between neutrophil and lymphocyte levels in the body, and it has a higher sensitivity than neutrophils and lymphocytes alone to indicate the state of systemic inflammation [35, 36]. Through a case-control study and a comprehensive meta-analysis based on previous evidence and our findings, we found that the value of NLR was higher in severe COVID-19 group than in the non-severe COVID-19 group. The risk of severe COVID-19 increased with increasing NLR. The initial NLR was a strong predictor of severe COVID-19. To our knowledge, our meta- analysis is the largest study to investigate whether the NLR could help predict the severity of COVID-19 early in the disease course.

The results of our analysis are consistent with previous studies. Previous meta-analyses that included 3 studies found that NLR was positively correlated with the severity of COVID-19 [37]. This result was also consistent with another meta-analysis that included 5 studies [38]. A difference in the initial NLR was also found between patients with and without COVID-19. Wang et al. discovered that the initial NLR was a great diagnostic indicator to distinguish COVID-19 [32]. Studies have reported that the NLR 
Fig. 5 The SROC of NLR in predicting severe COVID19. a Forest plot of the sensitivity; b Forest plot of the specificity; c the area under SROC and $Q$ index

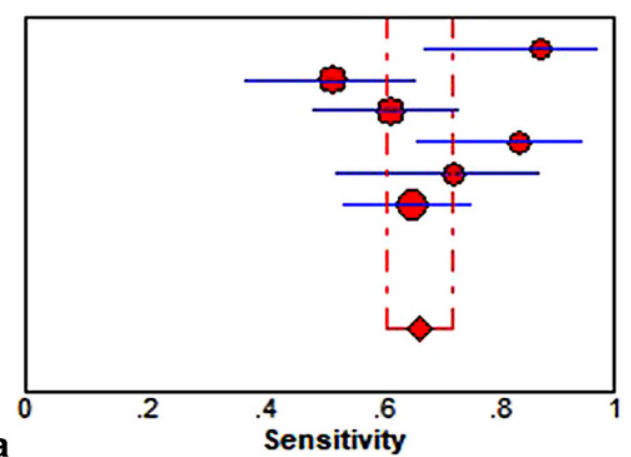

Yang et al.2020

Chen et al.2020

Wang et al.2020

Xia et al.2020

Huang et al.2020

Cheng et al.2020

Sensitivity $(95 \% \mathrm{Cl})$

$0.88 \quad(0.68-0.97)$

$0.52 \quad(0.37-0.66)$

$0.62(0.49-0.74)$

$0.84(0.66-0.95)$

$0.72 \quad(0.53-0.87)$

$0.65(0.54-0.76)$

Pooled Sensitivity $=0.67$ ( 0.61 to 0.72 )

Chi-square $=15.92 ; \mathrm{df}=5(\mathrm{p}=0.0071)$

Inconsistency (l-square) $=68.6 \%$

a

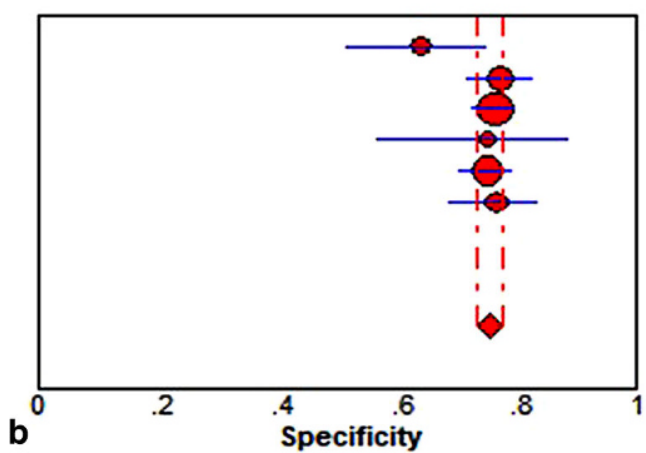

Yang et al.2020

Chen et al. 2020

Wang et al.2020

Xia et al. 2020

Huang et al. 2020

Cheng et al.2020

Specificity $(95 \% \mathrm{CI})$

$0.64 \quad(0.51-0.75)$

$0.77 \quad(0.71-0.83)$

$0.76 \quad(0.73-0.80)$

$0.75 \quad(0.57-0.89)$

$0.75 \quad(0.70-0.79)$

$0.77 \quad(0.68-0.83)$

Pooled Specificity $=0.75(0.73$ to 0.78$)$

Chi-square $=5.43 ;$ df $=5(p=0.3661)$

Inconsistency (l-square) $=7.8 \%$

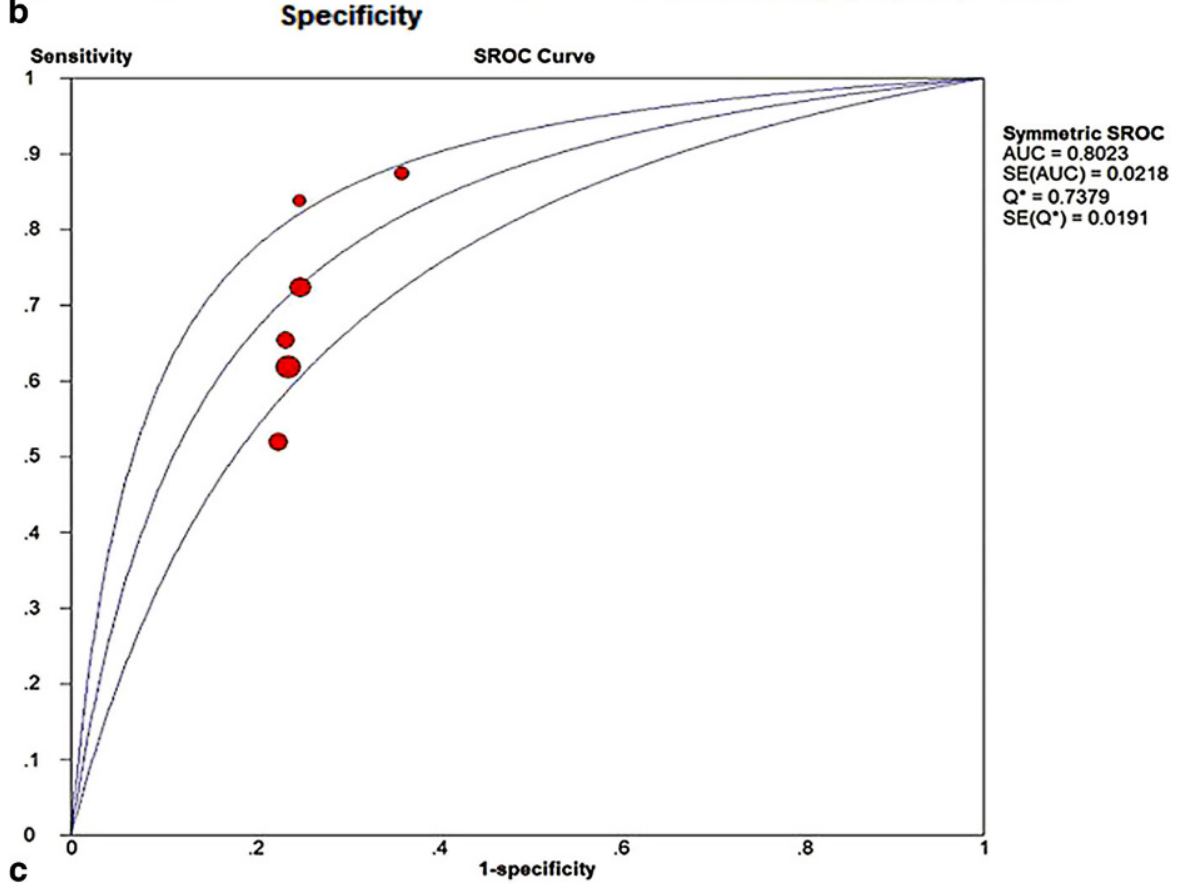

could be considered as an independent biomarker of a poor prognosis in patients with COVID-19. Liu et al. showed that the NLR was an independent risk factor for mortality in COVID-19 patients [21]; however, only two studies focused on mortality and NLR for COVID-19, which is too few to perform a meta-analysis. To further confirm the significance value of the NLR in the diagnostics, prediction of disease deterioration and clinical outcomes of COVID-19 patients, more studies are necessary.
There is a large body of evidence to suggest that age plays an important role in the disease development and prognosis of COVID-19. Study of Liu et al. declared that patients with aged greater than 50 years and with an NLR greater than 3.13 were more likely to develop severe COVID-19, and they suggested that these patients should be sent to the ICU as earlier as possible [11]. While comparing the analysis results from previously published articles, patient location caught our attention, and the clinical characteristics and prognosis were different among different districts 
[14]. Therefore, we performed a subgroup analysis according to the mean age ( $>50$ years or $\leq 50$ years) and study location (the study included patients in Hubei or not). The analysis showed that the mean age and the study location did not affect the predictive power of NLR for severe COVID-19. The transprovincial flow of patients should be taken into consideration when interpreting the results.

Several limitations exist in this study. First, the case-control study was conducted retrospectively, which has inherent biases although the data in the electronic data capture and analysis system were collected prospectively. Second, there were a few studies reporting the NLR of COVID-19 patients who could not be included in the final analyses due to insufficient data. Third, noticeable heterogeneity existed among studies included in the meta-analyses and was not fully eliminated, which might make the results less powerful.

\section{Conclusion}

The initial NLR was a great predictor of severe COVID19 and could help clinicians identify of potentially critical patients early and allocate of critical resources.

Acknowledgements We would like to thank all the medical workers involved in the rescue and the staff for collection of the data. The information of hospitals and investigators participated in the case-control study was showed in additional file 7 .

Author Contribution Jiangli Cheng: data curation, formal analysis, and writing original draft. Aijia Ma: formal analysis, writing original draft, writing review editing. Jing Yang: investigation, data curation, and writing original draft. Meiling Dong: data curation, validation, writing original draft. Xuelian Liao: data curation, formal analysis. Yan Kang: conceptualization, formal analysis, funding acquisition, investigation, supervision, writing review editing.

Funding The work was supported by Project of Novel Coronavirus Pneumonia in West China Hospital (HX2019nCoV027) and 1.3.5 project for disciplines of excellence, West China Hospital, Sichuan University (ZYGD18020).

\section{Declarations}

Conflict of interest J. Cheng, A. Ma, J. Yang, M. Dong, X. Liao and Y. Kang declare that they have no competing interests.

Ethical standards All procedures performed in studies involving human participants or on human tissue were in accordance with the ethical standards of the institutional and/or national research committee (Ethics Committee of the West China Hospital of Sichuan University and the participating hospitals) and with the 1975 Helsinki declaration and its later amendments or comparable ethical standards. Informed consent was obtained from all individual participants included in the study.

Open Access This article is licensed under a Creative Commons Attribution 4.0 International License, which permits use, sharing, adaptation, distribution and reproduction in any medium or format, as long as you give appropriate credit to the original author(s) and the source, provide a link to the Creative Commons licence, and indicate if changes were made. The images or other third party material in this article are included in the article's Creative Commons licence, unless indicated otherwise in a credit line to the material. If material is not included in the article's Creative Commons licence and your intended use is not permitted by statutory regulation or exceeds the permitted use, you will need to obtain permission directly from the copyright holder. To view a copy of this licence, visit http://creativecommons.org/licenses/by/4.0/.

\section{References}

1. Bedford J, Enria D, Giesecke J, et al. COVID-19: towards controlling of a pandemic. Lancet. 2020;395(10229):1015-8.

2. Huang C, Wang Y, Li X, et al. Clinical features of patients infected with 2019 novel coronavirus in Wuhan, China. Lancet. 2020;395(10223):497-506.

3. Yang X, Yu Y, Xu J, et al. Clinical course and outcomes of critically ill patients with SARS-CoV-2 pneumonia in Wuhan, China: a single-centered, retrospective, observational study. Lancet Respir Med. 2020;8(5):475-81.

4. Chen N, Zhou M, Dong X, et al. Epidemiological and clinical characteristics of 99 cases of 2019 novel coronavirus pneumonia in Wuhan, China: a descriptive study. Lancet. 2020;395(10223):507-13.

5. Yang Y, Lu Q, Liu M, et al. Epidemiological and clinical features of the 2019 novel coronavirus outbreak in China. 2020. MedRxiv.

6. Qin C, Zhou L, Hu Z, et al. Dysregulation of immune response in patients with COVID-19 in Wuhan, China. Clin Infect Dis. 2020;71(15):762-8. https://doi.org/10.1093/ $\mathrm{cid} / \mathrm{ciaa} 248$.

7. Faria SS, Fernandes PC Jr., Silva MJ, et al. The neutrophil-tolymphocyte ratio: a narrative review. ecancer. 2016;10:702.

8. Li W, Ai X, Ni Y, Ye Z, Liang Z. The association between the neutrophil-to-lymphocyte ratio and mortality in patients with acute respiratory distress syndrome: a retrospective cohortstudy. Shock. 2019;51(2):161-7.

9. RicheF, GayatE, BarthelemyR,LeDorzeM, MateoJ, PayenD. Reversal of neutrophil-to-lymphocyte count ratio in early versus late death from septic shock. Crit Care. 2015;19:439.

10. Huang Z, Fu Z, Huang W, et al. Prognostic value of neutrophil-to-lymphocyte ratio in sepsis: a meta-analysis. Am J Emerg Med. 2020;38(3):641-7. https://doi.org/10. 1016/j.ajem.2019.10.023.

11. Liu Y, Du X, Chen J, et al. Neutrophil-to-lymphocyte ratio as an independent risk factor for mortality in hospitalized patients with COVID-19. J Infect. 2020;81(1):e6-e12. https://doi.org/10.1016/j.jinf.2020.04.002.

12. Zhang BC, Zhou X, Zhu CL, et al. Immune phenotyping based onneutrophil-to-lymphocyte ratio and IgG predicts diseaseseverity and outcome for patients with COVID-19. 2020. medRxiv.

13. Wang CZ, Deng R, Gou LY, et al. Preliminary study to identify severe from moderate cases ofCOVID-19 using NLR\&RDWSD combination parameter. 2020. medRxiv.

14. Liao X, Chen H, Wang B, et al. Critical care for patients with severeCovid-2019inSichuan province, China-aprovincial cohortstudy. 2020. medRxiv.

15. Moher D, Liberati A, Tetzlaff J, PRISMA Group. Preferred reporting items for systematic reviews and meta-analyses: the PRISMA statement. Int J Surg. 2010;8(5):336-41. https://doi.org/10.1016/j.ijsu.2010.02.007.

16. Wells GA, Shea B, O'Connell D, et al. The Newcastle-Ottawa Scale (NOS) for assessing the quality of nonrandomised studies in meta-analyses. Oxford; 2018. 
17. Wan X, Wang W, Liu J, et al. Estimating the sample mean and standard deviation from the sample size, median, range and/or interquartile range. BMC Med Res Methodol. 2014;14:135. https://doi.org/10.1186/1471-2288-14-135.

18. Luo D, Wan X, Liu J, Tong T. Optimally estimating the sample mean from the sample size, median, mid-range, and/or mid-quartile range. Stat Methods Med Res. 2018;27(6):1785-805.

19. Duval S, Tweedie R. Trim and fill: a simple funnel-plotbased method of testing and adjusting for publication bias in meta-analysis. Biometrics. 2000;56(2):455-63.

20. Gong J, Ou J, Qiu XP, et al. A tool to early predict severe corona virus disease 2019 (COVID-19) : a multicenter study using the risknomogram in Wuhan and Guangdong, China. 2020. medRxiv.

21. Liu JY, Liu Y, Xiang P, et al. Neutrophil-to-lymphocyte ratio predicts severe illness patients with 2019 novel Coronavirus in the early stage. 2020. medRxiv.

22. YangAP, LiuJP, TaoWQ, LiHM. The diagnostic and predictive role of NLR, d-NLR and PLR in COVID-19 patients. Int Immunopharmacol. 2020;84:106504.

23. Zhang Y, Zheng L, Liu L, Zhao M, Xiao J, Zhao Q. Liver impairment in COVID-19 patients: a retrospective analysis of 115 cases from a single centre in Wuhan City, China. Liver Int. 2020;40(9):2095-103. https://doi.org/10.1111/ liv.14455.

24. Guo YB, Liu Y, Lu JT, et al. Development and validation of an early warning score (EWAS) for predicting clinical deterioration in patients with coronavirus disease 2019 . 2020. medRxiv.

25. Feng Z, Yu Q, Yao S, et al. Early prediction of disease progression in 2019 novel Coronavirus pneumonia patients outside Wuhan with CT and clinical characteristics. 2020. medRxiv.

26. ChenX, ZhengF, QingYH, etal. Epidemiological and clinical features of 291 cases with coronavirus disease 2019 in areas adjacent to Hubei, China: a double-center observational study. 2020. medRxiv.

27. Ma Y, Fan YP, et al. Predictive value of theneutrophilto-lymphocyte ratio(NLR) for diagnosis and worse clinical course of the COVID-19: findings from ten provinces in China. Lancet. 2020; https://doi.org/10.2139/ssrn. 3569838.

28. Huang YX, Xie J, Zang JL, et al. Analysis of 121 novel coronavirus pneumonia cases. J Pract Med. 2020;36(010):1282-5.
29. XiaX, Wen M,ZhanS,HeJ,ChenW.Anincreased neutrophil/ lymphocyteratiois an earlywarning signal of severeCOVID19. Nan Fang Yi Ke DaXueXue Bao. 2020;40(3):333-6.

30. Chen X, Xiang JH, et al. Retrospective study on the epidemiological characteristics of 139 patients withnovel coronavirus pneumonia on the effects of severity. Chongqing Med. 2020;49(17):2802-6.

31. Peng YD, Meng K, Guan HQ, et al. Clinical characteristics and outcomes of 112 cardiovascular disease patients infected by 2019-nCoV. Zhonghua Xin Xue Guan Bing Za Zhi. 2020;48:E4.

32. Liang W, Liang H, Ou L, et al. Development and validation of a clinical risk score to predict the occurrence of critical illnessinhospitalized patients with COVID-19. JAMAIntern Med. 2020;180(8):1-9.

33. Ewan C, Bendayan R, Daniel B, et al. Supplementing the national early warning score (NEWS2) for anticipating early deterioration among patients with COVID-19 infection. 2020. medRxiv.

34. Huang SP, Liu M, Li XL, et al. Significance of neutrophil-tolymphocyte ratio, platelet-to-lymphocyte ratio for predicting clinical outcomes in COVID-19. 2020. medRxiv.

35. Guthrie GJ, Charles KA, Roxburgh CS, Horgan PG, McMillan DC, Clarke SJ. The systemic inflammation-based neutrophil-lymphocyte ratio: experience in patients with cancer. Crit Rev Oncol Hematol. 2013;88(1):218-30.

36. Han Q, Wen X, Wang L, et al. Role of hematological parameters in the diagnosis of influenza virus infection in patients with respiratory tract infection symptoms. J Clin Lab Anal. 2020;34(5):e23191. https://doi.org/10.1002/jcla. 23191.

37. Zeng F, Li L, Zeng J, et al. Can we predict the severity of COVID-19 with a routine blood test? Pol Arch Intern Med. 2020;130(5):400-6. https://doi.org/10.20452/pamw. 15331.

38. Lagunas-Rangel FA. Neutrophil-to-lymphocyte ratio and lymphocyte-to-C-reactive protein ratio in patients with severe coronavirus disease 2019 (COVID-19): a metaanalysis. J Med Virol. 2020;92(10):1733-4. https://doi.org/ 10.1002/jmv.25819.

Publisher's Note Springer Nature remains neutral with regard to jurisdictional claims in published maps and institutional affiliations. 